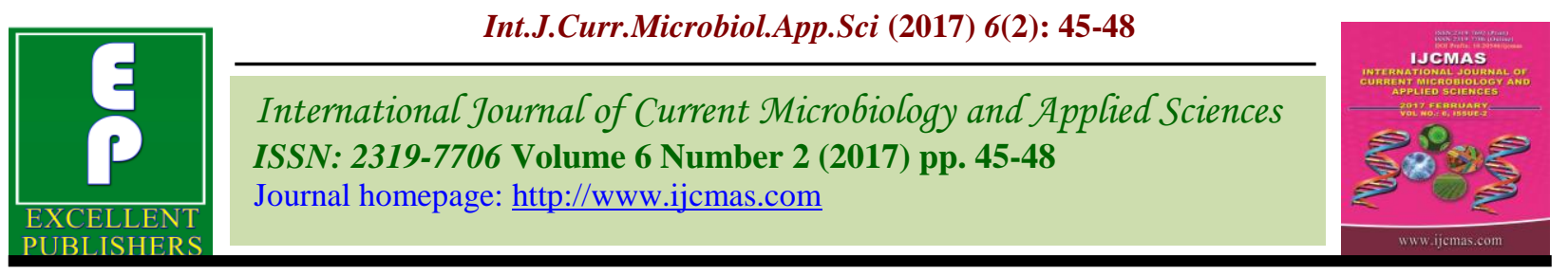

Original Research Article

http://dx.doi.org/10.20546/ijcmas.2017.602.006

\title{
Dietary Composition of Flathead Fish Cociella crocodila (Tilesius, 1812), In Hooghly Estuary, India
}

\author{
Shuvra Roy* \\ CAS Marine Biology, Annamalai University, Parangipettai, 608502 \\ Tamil Nadu, India \\ *Corresponding author
}

A B S T R A C T

\section{Keywords}

Dietary composition,

Stomatopods,

Crustacean,

Degree of fullness.

Article Info

Accepted:

05 January 2017

Available Online:

10 February 2017
The present study was aimed to analyse the dietary composition of Cociella crocodila in the Hooghly estuary, West Bengal. The fish sample was collected from the Kakdwip coast. As the fish was carnivorous so after analysis the gut, fishes, Stomatopods, Crustaceans and miscellaneous items were found. Stomatopods were found in the gut content dominantly during all the season followed by Crustaceans and fishes. Also analyse the degree of fullness of stomach of C. crocodila.

\section{Introduction}

Platycephalids (Order Scorpaeniformes) popularly known as flathead or crocodile fish, are found distributed in Indo Pacific and Atlantic and eastern Mediterranean regions (Imamura, 1996; Lee et al., 2003; Nelson, 2006). These fishes are available more in Hooghly estuarine region and are commercially valuable and popular food fishes in the fish market of Kakdwip. The flathead fishes can be distinguished from other fishes as it has elongated body, head moderately to strongly depressed with large mouth and the longer lower jaw. Though considerable quantities of flathead fish, Cociella crocodila (Family Platicephalidae) are landed in the study area, dietary detailed study on the composition of this species were made. The present study was aimed to understand the food preference pattern of the flat head C. crocodila off Hooghly estuary.

\section{Materials and Methods}

The Hooghly estuary (Lat. 21 ${ }^{\circ} 40^{\prime}$ and long $87^{\circ} 47^{\prime}$ E) fans out below Diamond Harbour from a width of $3.2 \mathrm{Km}$ at Kantaberia to 19.3 $\mathrm{Km}$ at the sea face. The Kakdwip region of Hooghly estuary is most diversified area of marine and brackish water fishes. A total of 200 species with recognizable stomach contents formed the basis for the study of food and feeding habits of $C$. crocodile. After measuring the length and weight of the collected samples those were dissected for removing guts for further analysis. The gut contents were weighed and cut open for 
recording degree of fullness of stomachs. Stomachs condition were classified based on the quantity of food material present in the gut as gorged, $3 / 4$ full, $1 / 2$ full, $1 / 4$ full, little and empty. Stomach content were emptied in a petri-dish and segregated to the study of composition. Quantitative and qualitative analysis was adopted and prey items in the recognisable condition were identified up to their species and generic level. Following the Volume displacement method (Pillai, 1952), volume of each food items were measured with using measuring jar. C. crocodila is a carnivorous species.

\section{Results and Discussion}

\section{Qualitative and quantitative analysis}

The details of qualitative and quantitative analysis of stomach content of $C$. crocodila are presented below:

The most important food items observed in the gut contents was Stomatopods (squilla). The highest quantity of squilla was found in post monsoon $(36.65 \%)$ and the lowest summer $(25.39 \%)$.

After fishes Prawns $(0.98 \%)$ formed the most important food items. highest quantities were found in the month of summer $(16.16 \%)$ and the lowest quantity found in monsoon $(8.0 \%)$. Next is the crabs $(0.99 \%)$ formed the most important food items. highest quantities were found in the month of summer (16.18\%) and the lowest quantity found in monsoon (7.84\%).

In remaining food items viz., fish remains semi digested matter, crustacean remains, shells were consumed in lesser quantities compare to the above groups. Semi digested matter formed an important constituents of food items in different proportion in all the months. The quantity of semi digested matter was maximum in monsoon (17.90\%) and minimum in post monsoon $(9.31 \%)$.

\section{Food and feeding habit}

A total number of 200 species with recognizable stomach contents formed the basis for the study of food and feeding habits of Cociella crocodila.

The qualitative and quantitative of food of $C$. crocodila showed that this species feeds mainly on crustaceans $(5.14 \%)$ and fish $(2.48 \%)$. The 'miscellaneous' $(1.34 \%)$ which formed the third group mainly consisted of crustaceans and fish remains. Based on the present study, it could be inferred that $C$. crocodila is carnivorous fish. The flat heads are bottom feeders and mainly feed on crustaceans and teleosts (Colefax, 1937; Chacko, 1949; Coleman and Mobley, 1984). The present study also reveals that $C$. crocodila is a bottom feeder, feeding mainly crustaceans and followed by the teleost.

Table.1 Qualitative and quantitative composition of the gut content of $C$. crocodile

\begin{tabular}{|l|c|c|c|}
\hline \multirow{2}{*}{ Food Items } & \multicolumn{3}{|c|}{ Seasons } \\
\cline { 2 - 4 } & Monsoon & Post monsoon & Summer \\
\hline Fishes & 29.55 & 28.75 & 24.61 \\
Stomatopods & 36.65 & 43.69 & 25.39 \\
Prawn & 8 & 8.67 & 16.16 \\
Crabs & 7.84 & 9.22 & 16.18 \\
Miscellaneous & 17.9 & 9.31 & 17.63 \\
\hline
\end{tabular}


Table.2 Percentage occurrence of $C$. crocodile in various degree of fullness of stomach

\begin{tabular}{|l|c|c|c|}
\hline \multicolumn{1}{|c|}{$\begin{array}{c}\text { Fullness of } \\
\text { stomach }\end{array}$} & \multicolumn{3}{c|}{ Season } \\
\cline { 2 - 4 } & Monsoon & Post monsoon & Summer \\
\hline No.of fish sampled & 44 & 54 & 50 \\
Gorged & 2.605 & 5.98 & 0.95 \\
Full & 14.17 & 9.22 & 1.07 \\
3/4 Full & 15.04 & 7.12 & 3.78 \\
1/2 Full & 22.12 & 14.60 & 7.75 \\
1/4 Full & 15.77 & 11.11 & 10.93 \\
Little & 1.58 & 4.33 & 3.02 \\
Empty & 27.78 & 47.14 & 71.33 \\
\hline
\end{tabular}

Fig.1 Qualitative and quantitative composition of the gut content of C. crocodile

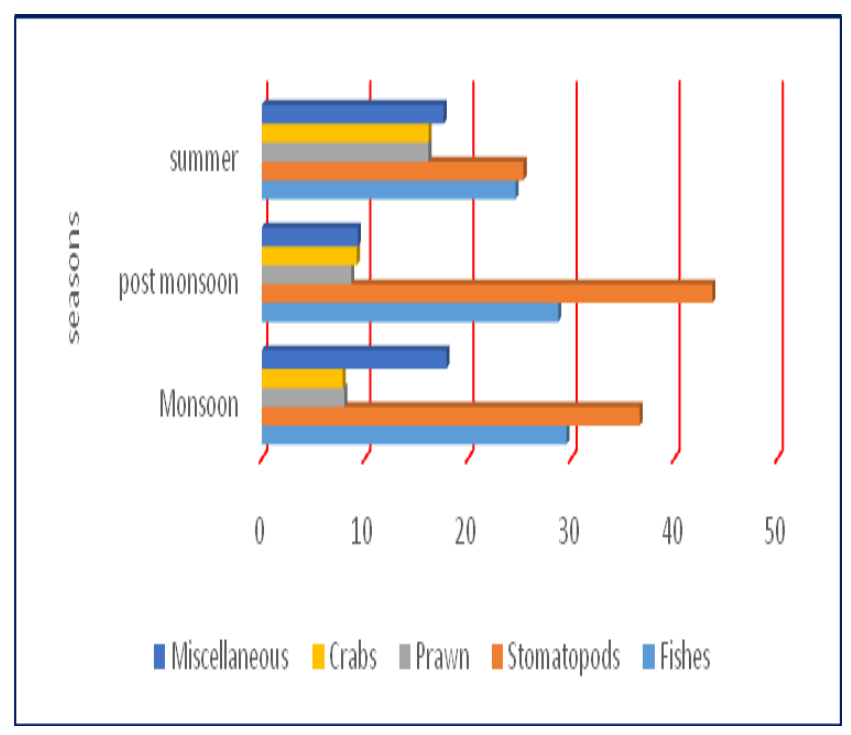

The food item crustaceans (prawns, squilla, and crabs) in the stomachs of $C$. crocodila in different months occurred in very high percentage and highest quantity of Crustaceans occurred during (57.73\%) followed by post monsoon $(61.58 \%)$ and monsoon (52.49\%). Squilla dominated among Crustaceans during February (43.69\%) and November $(36.65 \%)$, when the feeding intensity was very high. Prawn $(0.98 \%)$ was noticed the major food item among crustaceans during the month of summer was high $(16.16 \%)$ and low (8.67\%) in post monsoon.
Fig.2 Percentage occurrence of $C$. crocodile in various degree of fullness of stomach

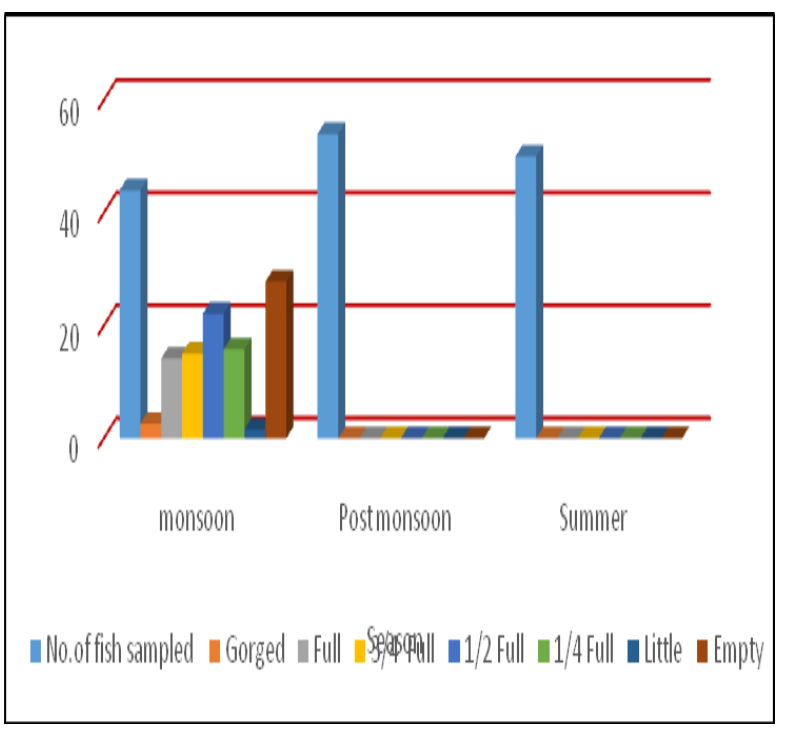

Highest percentage of crab was recorded in summer $(16.18 \%)$ and lowest $(7.84 \%)$ in monsoon. Rao (1964) had recorded as high as $82.6 \%$ of gut content of G. scaber as crustaceans. C. crocodila also preferred crustaceans as evident from the present study. The bottom feeders like S. sihama fed on crustacean (Honnegowda, 1984) in Kakdwip region. Coleman and Mobley (1984) noticed variation in the of food item of some platycephalids crustacean, cephalopods, fishes for sand flat heads $P$. bassensis, deep water flat head $P$. conatus and tiger flat head $N$, richardsoni. 


\section{Acknowledgement}

The author is grateful to the Dean and Director, CAS in Marine Biology and the authorities of Annamalai University for the facilities provided.

\section{References}

Chacko, P.I. 1949. Food and feeding of fishes of gulf of Mannar. Proc. Indian. Acd. Sci., 29B: 83-97.

Colefax, A.N. 1938. A preliminary investigation of the natural history of the tiger flat head Neoplatycephalus macrodon on the southeastern Australian coast. II. - Feding habits; breeding habits. Proc. Linn. Soc. N. S. W., 63: 55-94.

Coleman, N. and Mobley, M. 1984. Diets of commercially exploited fish from basss strait and adjacent victorian waters, southeastern Australia. Aust. J. Mar. Freshwat. Res., 35(5): 549-560

Honnegowda, H. 1984. Observation on the biology of the Indian sandwhiting, Sillago sihama (Forskal). Master of Fisheries Science, Thesis, University of
Agricultural Science, Bangalore. Pp. 148. Predator in Posidonia Australis Seagrass Bed. Aust. J. Mar. Freshwat. Res., 34(5): 745-754.

Imamura, H. 1996. Phylogeny of the family Platycephalidae and related taxa (Pisces: Scorpaeniformes). Species Div., 1(2): 123-233.

Lee, S.M., K.D. Kim and Lall, S.P. 2003. Utilization of glucose, maltose, dextrin and cellulose by juvenile flounder (Paralichthys olivaceus). Aquacult., 221: 427-438.

Nelson, J.S. 2006. Fishes of the world, fourth edition. John Wiley \& Sons, Inc., Hoboken, New Jersey. 624 Pp.

Rao, K.S. 1964. Food and feeding habits of fishes from the trawl catches from the Bay of Bengal with observation on diurnal variation in the nature of the feed. Ind. Fish., 11(1): 227-314.

Sainsbuy, K.J., Kailola, P.J. and Leyland, G.G. 1985. Continental shelf fishes of northern and northwestern Australia. Canberra: Clouston and Hall, Powanhall, Fisheries Information Service.

\section{How to cite this article:}

Shuvra Roy. 2017. Dietary Composition of Flathead Fish Cociella crocodila (Tilesius, 1812), In Hooghly Estuary, India. Int.J.Curr.Microbiol.App.Sci. 6(2): 45-48. doi: http://dx.doi.org/10.20546/ijcmas.2017.602.006 